\title{
Assessment of insulin sensitivity and secretion with the labelled intravenous glucose tolerance test: improved modelling analysis
}

\author{
A. Mari \\ Institute of Systems Science and Biomedical Engineering, National Research Council, Padova, Italy
}

Summary A new modelling analysis was developed to assess insulin sensitivity with a tracer-modified intravenous glucose tolerance test (IVGTT). IVGTTs were performed in 5 normal (NGT) and 7 non-insulin-dependent diabetic (NIDDM) subjects. A $300 \mathrm{mg} / \mathrm{kg}$ glucose bolus containing $\left[6,6-{ }^{2} \mathrm{H}_{2}\right]$ glucose was given at time 0 . After $20 \mathrm{~min}$, insulin was infused for $5 \mathrm{~min}$ (NGT, 0.03; NIDDM, $0.05 \mathrm{U} / \mathrm{kg}$ ). Concentrations of tracer, glucose, insulin and C-peptide were measured for $240 \mathrm{~min}$. A circulatory model for glucose kinetics was used. Glucose clearance was assumed to depend linearly on plasma insulin concentration delayed. Model parameters were: basal glucose clearance $\left(\mathrm{Cl}_{\mathrm{b}}\right)$, glucose clearance at $600 \mathrm{pmol} / \mathrm{l}$ insulin concentration $\left(\mathrm{Cl}_{600}\right)$, basal glucose production $\left(\mathrm{P}_{\mathrm{b}}\right)$, basal insulin sensitivity index $\left(\mathrm{BSI}=\mathrm{Cl}_{\mathrm{b}} /\right.$ basal insulin concentration); incremental insulin sensitivity index (ISI = slope of the relationship between insulin concentration and glucose clearance). Insulin secretion was calculated by deconvolution of C-peptide data. Indices of basal pancreatic sensitivity $\left(\mathrm{PSI}_{\mathrm{b}}\right)$ and first $\left(\mathrm{PSI}_{1}\right)$ and second-phase $\left(\mathrm{PSI}_{2}\right)$ sensitivity were calculated by normalizing insulin secretion to the prevailing glucose levels. Diabetic subjects were found to be insulin resistant (BSI: $2.3 \pm 0.6$ vs $0.76 \pm 0.18 \mathrm{ml} \cdot \mathrm{min}^{-1} \cdot \mathrm{m}^{-2} \cdot \mathrm{pmol} / \mathrm{l}^{-1}, p<0.02$; ISI:
$0.40 \pm 0.06$ vs $0.13 \pm 0.05 \mathrm{ml} \cdot \mathrm{min}^{-1} \cdot \mathrm{m}^{-2} \cdot \mathrm{pmol} / \mathrm{l}^{-1}$, $p<0.02 ; \mathrm{Cl}_{600}: 333 \pm 47$ vs $137 \pm 26 \mathrm{ml} \cdot \mathrm{min}^{-1} \cdot \mathrm{m}^{-2}$, $p<0.01$; NGT vs NIDDM). $\mathrm{P}_{\mathrm{b}}$ was not elevated in NIDDM $\left(588 \pm 169\right.$ vs $606 \pm 123 \mu \mathrm{mol} \cdot \mathrm{min}^{-1} \cdot \mathrm{m}^{-2}$, NGT vs NIDDM). Hepatic insulin resistance was however present as basal glucose and insulin were higher. PSI $_{1}$ was impaired in NIDDM $(67 \pm 15$ vs $12 \pm 7 \mathrm{pmol} \cdot \mathrm{min}^{-1} \cdot \mathrm{m}^{-2} \cdot \mathrm{mmol} / \mathrm{l}^{-1}, p<0.02$; NGT vs NIDDM). In NGT and in a subset of NIDDM subjects $(n=4)$, PSI $_{\mathrm{b}}$ was inversely correlated with BSI ( $r=0.95, p<0.0001, \log$ transformation). This suggests the existence of a compensatory mechanism that increases pancreatic sensitivity in the presence of insulin resistance, which is normal in some NIDDM subjects and impaired in others. In conclusion, using a simple test the present analysis provides a rich set of parameters characterizing glucose metabolism and insulin secretion, agrees with the literature, and provides some new information on the relationship between insulin sensitivity and secretion. [Diabetologia (1998) 41: 1029-1039]

Keywords Insulin sensitivity, insulin secretion, insulin resistance, non-insulin-dependent diabetes mellitus, intravenous glucose tolerance test, glucose kinetics, mathematical models.
Received: 17 September 1997 and in final revised form: 28 April 1998

Corresponding author: Dr. A. Mari, LADSEB-CNR, corso Stati Uniti 4, I-35127 Padova, Italy

Abbreviations: IVGTT, Intravenous glucose tolerance test; NGT, normal glucose tolerance; NIDDM, non-insulin-dependent diabetes mellitus; MTT, mean transit time; V, whole body glucose distribution volume; BSI, basal insulin sensitivity index; ISI, incremental insulin sensitivity index; ISR, insulin secretion rate; PSI, pancreatic sensitivity index; $\mathrm{Cl}$, glucose clearance.
In the study of diabetes mellitus, the availability of a simple test for assessing the function of the key organs involved in glucose homeostasis, beta cells, muscle and liver, would be of remarkable value. A test appealing for its experimental simplicity is the intravenous glucose tolerance test (IVGTT), which provides information on beta-cell function and insulin sensitivity (both peripheral and hepatic, if a glucose tracer is used). However, the test simplicity is counterbalanced by the necessity to use a model for the analysis 
Table 1. Characteristics of the subjects

\begin{tabular}{|c|c|c|c|c|c|c|}
\hline & $\begin{array}{l}\text { Age } \\
\text { (years) }\end{array}$ & $\begin{array}{l}\text { Body weight } \\
\text { (kg) }\end{array}$ & $\begin{array}{l}\mathrm{BMI}^{\mathrm{a}} \\
\left(\mathrm{kg} / \mathrm{m}^{2}\right)\end{array}$ & $\begin{array}{l}\mathrm{HbA}_{1 \mathrm{c}}^{\mathrm{b}} \\
(\%)\end{array}$ & $\begin{array}{l}\text { Fasting glucose } \\
(\mathrm{mmol} / \mathrm{l})\end{array}$ & $\begin{array}{l}\text { Fasting insulin } \\
(\mathrm{pmol} / \mathrm{l})\end{array}$ \\
\hline Normal glucose tolerance & $24 \pm 2$ & $73 \pm 6$ & $25 \pm 1$ & $4.3 \pm 0.4$ & $5.2 \pm 0.1^{\mathrm{c}}$ & $50 \pm 5^{\mathrm{d}}$ \\
\hline NIDDM & $49 \pm 5$ & $81 \pm 3$ & $27 \pm 1$ & $8.0 \pm 0.5$ & $8.6 \pm 0.8^{c}$ & $125 \pm 27^{\mathrm{d}}$ \\
\hline
\end{tabular}

Data are mean \pm SEM

${ }^{\mathrm{a}}$ Body mass index (body weight/height ${ }^{2}$ ); ${ }^{\mathrm{b}}$ glycated haemoglobin; ${ }^{\mathrm{c}} p<0.005 ;{ }^{\mathrm{d}} p<0.05$

Normal glucose tolerance vs NIDDM

of data. The most widely used model for this purpose, the minimal model by Bergman and colleagues [1], has known drawbacks that limit the reliability of the approach $[2,3]$. Therefore, the potential advantages of the IVGTT over alternative tests have not been fully exploited. In the presence of modelling problems, the IVGTT is not competitive with the hyperglycaemic glucose clamp, which is more laborious but avoids modelling difficulties.

This work was undertaken to overcome the major problems of minimal model analysis, while retaining the experimental simplicity of the IVGTT. These problems arise from the excessive model simplifications, the major limitations being the monocompartmental assumption for glucose kinetics and the inadequate representation of glucose production $[2,3]$. The analysis of the IVGTT has thus been improved in two directions. First, a glucose tracer was used to circumvent the problem of modelling glucose production. Second, a model of glucose kinetics was developed that better represents the physiology of the glucose system. Using a tracer and an appropriate model, physiological parameters could be estimated, such as steady-state glucose clearance at various insulin levels (and derived insulin sensitivity indices), glucose distribution volume, and glucose production. In parallel, beta-cell function was evaluated by deconvolution of C-peptide data according to the approach developed by Van Cauter et al. [4]. The resulting analysis, featuring a rich set of physiological indices of insulin secretion and action, is competitive with the analogous analysis based on the combination of the hyperglycaemic glucose clamp and the tracer method. The advantage of greater experimental simplicity of the IVGTT may thus become a reason of preference in some instances, as the major defects of the more traditional IVGTT-based analyses are eliminated.

\section{Subjects, materials and methods}

The tracer-modified IVGTT data analysed in this work have been kindly provided by the Department of Clinical and Experimental Medicine of the University of Padova, Italy. Data on normal subjects have been reported previously [5].

Subjects. Five normal (NGT) and seven non-insulin-dependent diabetic (NIDDM) subjects were recruited from the diabetic clinic at Padova University Hospital. Their characteristics are shown in Table 1. In NIDDM subjects, the glycaemic control was achieved with diet alone or with diet and sulfonylurea or biguanide preparations. Pharmacological treatment was stopped at least 3 days before the study. All subjects followed an isocaloric diet, recorded by a dietitian, with three meals daily (50\% carbohydrate, $35 \%$ fat, and $15 \%$ protein) for at least 30 days before the study. The daily caloric intake was approximately $2000 \mathrm{kcal} /$ day.

Experimental protocol. On the day of the study, after an overnight fast, at 07.00 hours the subjects were admitted to the hospital. At 07.30 hours, a 20-gauge butterfly needle was inserted into a dorsal hand vein for blood sampling. The hand was placed in a box heated to approximately $60^{\circ} \mathrm{C}$ to arterialize venous blood. The patency of the needle was maintained with a controlled saline infusion throughout the study. An 18-gauge cannula was placed into the contralateral antecubital vein for injection of the labelled glucose load and insulin infusion. After $30 \mathrm{~min}$ rest, $3 \mathrm{ml}$ basal blood samples were collected at $-30,-15$, and $0 \mathrm{~min}$. At $0 \mathrm{~min}$, immediately after the collection of the last basal sample, a $0.3 \mathrm{~g} / \mathrm{kg}$ glucose bolus containing a glucose tracer (approximately $10 \%$ of $\left[6,6-{ }^{2} \mathrm{H}_{2}\right]$ glucose, Tracer Technology, Sommerville, Mass., USA) was injected. At $20 \mathrm{~min}$, insulin was infused in the antecubital vein at a constant rate for $5 \mathrm{~min}$. A total of 0.03 (NGT) or 0.05 (NIDDM) U/kg of insulin was infused. Blood samples $(3 \mathrm{ml})$ were collected at $2,3,4,5,6,8,10,15,20,25,30,40,60,80,100,120,140,160$, 180,210 , and $240 \mathrm{~min}$ for the measurement of glucose, [6,6${ }^{2} \mathrm{H}_{2}$ ]glucose, insulin, and C-peptide concentrations. The experimental protocol was approved by the ethical committee of the University Hospital of Padova.

Analytical methods. Plasma glucose was measured with a glucose oxidase method using a Beckman glucose analyser (Fullerton, California, USA). Plasma insulin and C-peptide were measured by conventional radioimmunoassay [6]. Glycated haemoglobin $\left(\mathrm{HbA}_{1 \mathrm{C}}\right)$ was determined by ion-exchange highperformance liquid chromatography [7] (normal range: $4.5-6 \%$ ). Glucose mass spectra were determined by gas chromatography-mass spectrometry of the pentaacetate derivative as described previously [8]. The quadrupole gas chromatography-mass spectrometry instrument (Hewlett-Packard 5988, Milano, Italy) operated in electron impact mode by selected ion monitoring after isothermal separation at $250^{\circ} \mathrm{C}$ on a $30 \mathrm{~m}$ J\&W capillary column (San Francisco, California, USA). The monitored mass to charge ratios of the selected glucose pentaacetate derivative fragment were 242,243 , and 244 . The ratio of the areas of the spectral peaks at 244 and 242 (peak area ratio) was used in tracer calculations (see below). The 244/242 peak area ratios were measured in all blood samples and in the injected glucose dose.

Tracer calculations. The measured plasma glucose concentration is the sum of an exogenous component, originating from the injection of exogenous glucose, and an endogenous compo- 


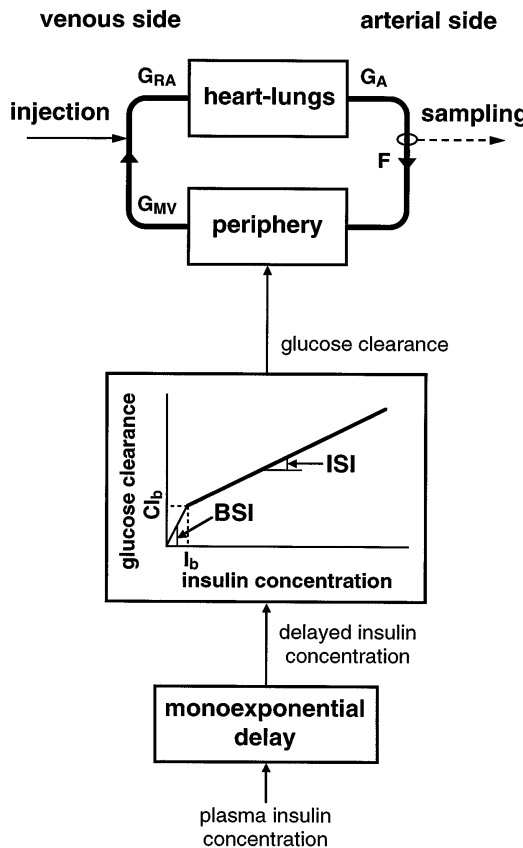

Fig. 1. The circulatory model of glucose kinetics (top) and the model of insulin action (bottom). In the circulatory model, $\mathrm{F}$ is cardiac output, $\mathrm{G}_{\mathrm{A}}, \mathrm{G}_{\mathrm{MV}}$ and $\mathrm{G}_{\mathrm{RA}}$ are arterial, mixed-venous, and right atrium glucose concentrations, respectively. The relationship between insulin concentration and glucose clearance is included in the model of insulin action. This relationship is a straight line, the leftmost extremity of which represents basal insulin concentration $\left(\mathrm{I}_{\mathrm{b}}\right)$ and basal glucose clearance $\left(\mathrm{Cl}_{\mathrm{b}}\right)$. The basal (BSI) and incremental (ISI) insulin sensitivity indices represent the slopes graphically indicated in the figure

nent, originating from glucose production. These two concentration components were calculated from the tracer-to-tracee ratios in the plasma samples and in the injected glucose dose. The tracer-to-tracee ratios were calculated using the 244/242 peak area ratios according to the equations of Rosenblatt et al. [9]. Exogenous glucose concentration was used in the modelling analysis.

Modeling analysis. Modelling analysis of the IVGTT data was based on a circulatory model of glucose kinetics [10-13], and on tracer kinetic methods derived from Zierler's methods for the study of organ kinetics $[14,15]$.

Model structure. Figure 1 (top) shows the circulatory model of glucose kinetics. The body tissues are lumped into two blocks. The upper block of Figure 1 (heart-lungs block) represents the heart chambers and the lungs, i.e. the tissues in between the right atrium and the left ventricle. The lower block of Figure 1 (periphery block) represents all the remaining tissues, nourished by the entire arterial tree originating from the left ventricle (including the heart tissues nourished by the coronaries). Blood flow for both blocks is cardiac output. In the experimental configuration adopted here, glucose is injected at the venous side, while blood is sampled at the arterial side (as indicated in Fig. 1).

Basic kinetic analysis. The two tissue blocks of Figure 1 can be regarded as single inlet-single outlet organs, coupled in a feedback arrangement. The basis of the mathematical description of a block (or of an organ) is its impulse response [14-16].
The impulse response is the tracer efflux (concentration times blood flow) observed at the organ outlet after a bolus injection of a unit tracer dose at the organ inlet (this definition assumes tracer does not recirculate). For any influx, the efflux is the convolution of the influx with the impulse response. As long as blood flow is constant, the same convolution relationship holds between inlet and outlet concentration, i.e.

$\mathrm{C}_{\text {out }}(\mathrm{t})=\int_{-\infty}^{\mathrm{t}} \mathrm{r}(\mathrm{t}-\tau) \mathrm{C}_{\text {in }}(\tau) \mathrm{d} \tau$

where $r(t)$ is the impulse response (units: $\min ^{-1}$ ), and $C_{\text {in }}(t)$ and $\mathrm{C}_{\text {out }}(\mathrm{t})$ are inlet and outlet concentrations, respectively.

The classical kinetic parameters are calculated from the impulse response $\mathrm{r}(\mathrm{t})$ [16]. The fractional extraction (E, dimensionless or \%) is 1 - the area under $\mathrm{r}(\mathrm{t})$; the clearance $(\mathrm{Cl}, \mathrm{ml}$. $\min ^{-1} \cdot \mathrm{m}^{-2}$, if normalized to body surface area), is the product of blood flow $\left(\mathrm{F}, \mathrm{ml} \cdot \mathrm{min}^{-1} \cdot \mathrm{m}^{-2}\right)$ and fractional extraction $(\mathrm{Cl}=\mathrm{F} \times \mathrm{E})$; the mean transit time (MTT, min) is the integral from zero to infinity of the product $\mathrm{t} \times \mathrm{r}(\mathrm{t})$, divided by the area under $\mathrm{r}(\mathrm{t})$; the distribution volume $(\mathrm{V}, \mathrm{ml} / \mathrm{kg})$ equals the product of blood flow, (1-fractional extraction) and mean transit time $[\mathrm{V}=\mathrm{F} \times(1-\mathrm{E}) \times \mathrm{MTT}][11]$.

Cardiac output. Cardiac output, expressed as flow of blood per square meter of body surface area, was assumed to be $3200 \mathrm{ml}$. $\mathrm{min}^{-1} \cdot \mathrm{m}^{-2}$ [17]. Since glucose concentration is measured in plasma, this cardiac output value was corrected using the ratio between glucose concentration in whole blood and in plasma (0.84). The value used was thus $\mathrm{F}=3200 \times 0.84 \mathrm{ml} \cdot \mathrm{min}^{-1}$. $\mathrm{m}^{-2}$, which ensures that the product of concentration and flow gives the actual glucose flux. A constant cardiac output value during the IVGTT was assumed.

Heart-lungs impulse response. For glucose, the heart-lungs system basically works as a small mixing compartment. A simple monoexponential impulse response for this block was thus adopted, i.e.

$r_{H L}(t)=\lambda e^{-\lambda t}$

Since the glucose fractional extraction in the heart-lungs system is negligible (i.e. zero in practice), the area under $r_{H L}(t)$ must be 1 . This is ensured by Eq. 2 , as $\lambda$ is both the coefficient and the exponent of the exponential function.

The constant $\lambda$ is the reciprocal of the mean heart-lungs transit time [16], and thus equals the ratio of blood flow (cardiac output) and volume. It was calculated by assuming a glucose volume of $700 \mathrm{ml}$ per $\mathrm{m}^{2}$ of body surface area and the cardiac output value reported above. This volume value (equivalent to $17 \mathrm{ml} / \mathrm{kg}$ of body weight for a subject of $70 \mathrm{~kg}$ and $1.7 \mathrm{~m}^{2}$ body surface area) was derived from published data [18-20]. The resulting value was $\lambda=3200 \times 0.84 / 700=$ $3.84 \mathrm{~min}^{-1}$. During the IVGTT, the heart-lungs impulse response was assumed to be invariant, as cardiac output was assumed to be constant.

Periphery impulse response. The impulse response of the periphery block was represented as a two-exponential function. The standard two-exponential function $\mathrm{A}_{1} \mathrm{e}^{-\alpha_{1} t}+\mathrm{A}_{2} \mathrm{e}^{-\alpha_{2} \mathrm{t}}$ was rearranged as

$r_{P}(t)=\left[\vartheta \alpha_{1} e^{-\alpha_{1} t}+(1-\vartheta) \alpha_{2} e^{-\alpha_{2} t}\right](1-E)$

In this particular representation, $\alpha_{1}$ and $\alpha_{2}$ are the exponents of the two exponential terms, $\mathrm{E}$ is the fractional extraction [i.e. 1$\mathrm{E}$ is the integral from zero to infinity of $\left.\mathrm{r}_{\mathrm{P}}(\mathrm{t})\right]$, and $\vartheta$ is the relative contribution of the first exponent to the area under the im- 
pulse response. Note in fact that the integral from zero to infinity of the term in square brackets is $\vartheta+(1-\vartheta)=1$ (the integral from zero to infinity of $\alpha \mathrm{e}^{-\alpha \mathrm{t}}$ is 1 ).

In the IVGTT experiment, the periphery impulse response changes with time as an effect of the transient increase of insulin concentration. It was assumed that insulin increases the fractional extraction $\mathrm{E}$, while the other parameters $\left(\alpha_{1}, \alpha_{2}\right.$ and $\vartheta)$ remain constant.

Model of insulin action. The action of insulin on glucose kinetics was modelled as a delayed effect of insulin on the whole-body fractional extraction, or equivalently on glucose clearance (see Fig. 1, bottom). It was assumed that $\mathrm{E}(\mathrm{t})$ depends linearly on a variable $\mathrm{Z}(\mathrm{t})$ that is related to the increment from the basal level of plasma insulin concentration by the differential equation

$\frac{\mathrm{dZ}(\mathrm{t})}{\mathrm{dt}}=-\beta \mathrm{Z}(\mathrm{t})+\beta\left[\mathrm{I}(\mathrm{t})-\mathrm{I}_{\mathrm{b}}\right]$

where $\mathrm{I}(\mathrm{t})$ is insulin concentration, $\mathrm{I}_{\mathrm{b}}$ is basal insulin concentration, and $\beta\left(\mathrm{min}^{-1}\right)$ is the parameter that determines the delay. The half-time for insulin action $(\min )$ is $(\ln 2) / \beta$. During the IVGTT, $\mathrm{Z}(\mathrm{t})$ starts from zero, follows the changes of insulin concentration in a delayed fashion, and returns to zero by the end of the IVGTT. In steady state $\mathrm{Z}(\mathrm{t})$ equals the insulin concentration increment, i.e. $\mathrm{Z}(\mathrm{t})$ has the same scale as the insulin concentration increment.

The assumed relationship between $\mathrm{Z}(\mathrm{t})$ and the wholebody fractional extraction $\mathrm{E}(\mathrm{t})$ is

$\mathrm{E}(\mathrm{t})=\mathrm{E}_{\mathrm{b}}+\gamma \mathrm{Z}(\mathrm{t})$

where $E_{b}$ is the basal fractional extraction and $\gamma$ is a parameter. The whole-body fractional extraction must satisfy the constraint $0<\mathrm{E}(\mathrm{t})<1$. When the insulin concentration is constant with time, Eq. 5 expresses the relationship between glucose clearance and insulin concentration at steady state. Since glucose clearance is the product of cardiac output and fractional extraction $(\mathrm{Cl}=\mathrm{F} \times \mathrm{E})$, from Eq. 5 one obtains

$\mathrm{Cl}=\mathrm{Cl}_{\mathrm{b}}+\mathrm{F} \gamma\left[\mathrm{I}-\mathrm{I}_{\mathrm{b}}\right]=\mathrm{Cl}_{\mathrm{b}}+\mathrm{ISI} \times\left[\mathrm{I}-\mathrm{I}_{\mathrm{b}}\right]$

where $\mathrm{Cl}$ is glucose clearance at the insulin concentration $\mathrm{I}$, and $\mathrm{Cl}_{\mathrm{b}}=\mathrm{F} \times \mathrm{E}_{\mathrm{b}}$ is the basal glucose clearance. The factor $\mathrm{F} \gamma$ is the slope of the relationship between insulin concentration and glucose clearance, and is thus an insulin sensitivity index. This index is denoted here as incremental insulin sensitivity index (ISI). Eq. 6 is graphically illustrated in Figure 1.

Whole-body response and parameter estimation. The wholebody response is the time course of exogenous glucose concentration during the IVGTT predicted by the circulatory model. It is obtained by combining the impulse responses of the heart-lungs and periphery blocks (Eqs. 2-3) and the model of insulin action (Eqs. 4-5), as detailed in Appendix A.

The six parameters of the whole-body response $\left(\alpha_{1}, \alpha_{2}, \beta, \gamma\right.$, $\vartheta$ and $\left.\mathrm{E}_{\mathrm{b}}\right)$ were estimated by least squares fit of the measured exogenous glucose concentration [5]. An estimate of the standard deviation of the parameters was obtained from the least squares algorithm.

Calculated physiological parameters. Physiologically meaningful parameters were calculated from the estimated model parameters. Parameters that need to be normalized to body size were expressed per square meter of body surface area. Glucose clearance was calculated at two insulin levels using Eq. 6. Basal glucose clearance $\left(\mathrm{Cl}_{\mathrm{b}}, \mathrm{ml} \cdot \mathrm{min}^{-2} \cdot \mathrm{m}^{-2}\right)$ was calculated as $\mathrm{Cl}_{\mathrm{b}}=$ $\mathrm{F} \times \mathrm{E}_{\mathrm{b}}$. Glucose clearance at $600 \mathrm{pmol} / \mathrm{l}\left(\mathrm{Cl}_{600}, \mathrm{ml} \cdot \mathrm{min}^{-1}\right.$. $\mathrm{m}^{-2}$ ) was calculated as $\mathrm{Cl}_{600}=\mathrm{Cl}_{\mathrm{b}}+\mathrm{F} \gamma\left(600-\mathrm{I}_{\mathrm{b}}\right)$. The mean transit time of the periphery block (MTT, min) was calculated from the exponential impulse response (Eq. 3) with standard formulae [16]. The whole-body glucose distribution volume in basal conditions $\left(\mathrm{V}, \mathrm{ml} / \mathrm{m}^{2}\right)$ was calculated as the sum of the volumes of the heart-lungs block $\left(700 \mathrm{ml} / \mathrm{m}^{2}\right)$ and of periphery block, calculated as $\mathrm{F} \times\left(1-\mathrm{E}_{\mathrm{b}}\right) \times \mathrm{MTT}$ [11], i.e. $\mathrm{V}=700+\mathrm{F} \times(1-$ $\left.\mathrm{E}_{\mathrm{b}}\right) \times$ MTT. Basal glucose production $\left(\mathrm{P}_{\mathrm{b}}, \mu \mathrm{mol} \cdot \mathrm{min}^{-1} \cdot \mathrm{m}^{-2}\right)$ was calculated as $P_{b}=C l_{b} G_{b}$, where $G_{b}$ is basal glucose concentration.

Peripheral insulin sensitivity indexes. Two indices of peripheral insulin sensitivity were calculated. A basal insulin sensitivity index $\left(\mathrm{BSI}, \mathrm{ml} \cdot \mathrm{min}^{-1} \cdot \mathrm{m}^{-2} \cdot \mathrm{pmol} / \mathrm{l}^{-1}\right)$ was calculated as the ratio between basal glucose clearance and basal insulin concentration, i.e. $\mathrm{BSI}=\mathrm{Cl}_{\mathrm{b}} / \mathrm{I}_{\mathrm{b}}$. An incremental insulin sensitivity in$\operatorname{dex}(\mathrm{ISI})\left(\mathrm{ml} \cdot \mathrm{min}^{-1} \cdot \mathrm{m}^{-2} \cdot \mathrm{pmol} / \mathrm{l}^{-1}\right)$ was calculated as the slope of the linear relationship between glucose clearance and insulin concentration (see Eq. 6 above). The meaning of these indices is graphically illustrated in Figure 1.

Comparison with the minimal model. To compare the circulatory model with the minimal model, the most favourable conditions for the minimal model have been chosen. Tracer data (exogenous glucose concentration) were used to estimate the minimal model parameters. From $\mathrm{S}_{\mathrm{G}}, \mathrm{S}_{\mathrm{I}}$, and the minimal model volume $\mathrm{V}_{\mathrm{mm}}$, the minimal model estimate of the basal glucose clearance, $\mathrm{V}_{\mathrm{mm}} \mathrm{S}_{\mathrm{G}}$, and of the insulin sensitivity index, $\mathrm{V}_{\mathrm{mm}} \mathrm{S}_{\mathrm{I}}$, were calculated [21]. These parameters are directly comparable with $\mathrm{Cl}_{\mathrm{b}}$ and ISI, as the model of insulin action is the same in the minimal model and in the circulatory model.

In this analysis, the first glucose samples ( $t \leq 5 \mathrm{~min})$ were not considered. To avoid possible differences due to the interpolation of insulin concentration, the insulin concentration profile used with the circulatory model was also used with the minimal model. From the minimal model estimate of the basal glucose clearance and of the insulin sensitivity index, a basal insulin sensitivity index, and glucose clearance at $600 \mathrm{pmol} / \mathrm{l}$ were calculated as for the circulatory model.

Calculation of insulin secretion. Insulin secretion rate (ISR, $\mathrm{pmol} \cdot \mathrm{min}^{-1} \cdot \mathrm{m}^{-2}$, normalized to body surface area) was calculated by deconvolution of C-peptide concentration [22]. The parameters of the two-exponential C-peptide impulse response were individualized on the basis of the group (NGT or NIDDM), sex, age, and body surface area, as proposed by Van Cauter et al. [4]. ISR was calculated by deconvolution during the basal period ( $\left(\mathrm{SR}_{\mathrm{b}}\right.$ ), every $2 \mathrm{~min}$ for the first $20 \mathrm{~min}$ of the IVGTT, every $5 \mathrm{~min}$ for a successive interval of $40 \mathrm{~min}$, and finally every $10 \mathrm{~min}$ for the remainder of the test. In the least-squares deconvolution algorithm, spurious oscillations of ISR were avoided by a penalty term based on the second derivative of ISR.

From the insulin secretion profile, two integral indexes of insulin secretion were obtained. An index of the first-phase insulin secretion ( $\mathrm{ISR}_{1}, \mathrm{pmol} \cdot \mathrm{min}^{-1} \cdot \mathrm{m}^{-2}$ ) was obtained as the integral mean of insulin secretion above the basal value from 0 to 6 min after glucose injection, as the first secretion peak was confined in this time interval. An index of the second-phase insulin secretion $\left(\mathrm{ISR}_{2}, \mathrm{pmol} \cdot \mathrm{min}^{-1} \cdot \mathrm{m}^{-2}\right.$ ) was obtained as the integral mean of insulin secretion above the basal value from 6 min after glucose injection to the time instant at which glucose concentration fell below the basal level (30-40 min in NGT and 40-120 min in NIDDM).

Pancreatic sensitivity indices. Three indices of pancreatic sensitivity to glucose were calculated. A basal pancreatic sensitivity index $\left(\mathrm{PSI}_{\mathrm{b}}, \mathrm{pmol} \cdot \mathrm{min}^{-1} \cdot \mathrm{m}^{-2} \cdot \mathrm{mmol} / \mathrm{l}^{-1}\right)$ was calculated as 

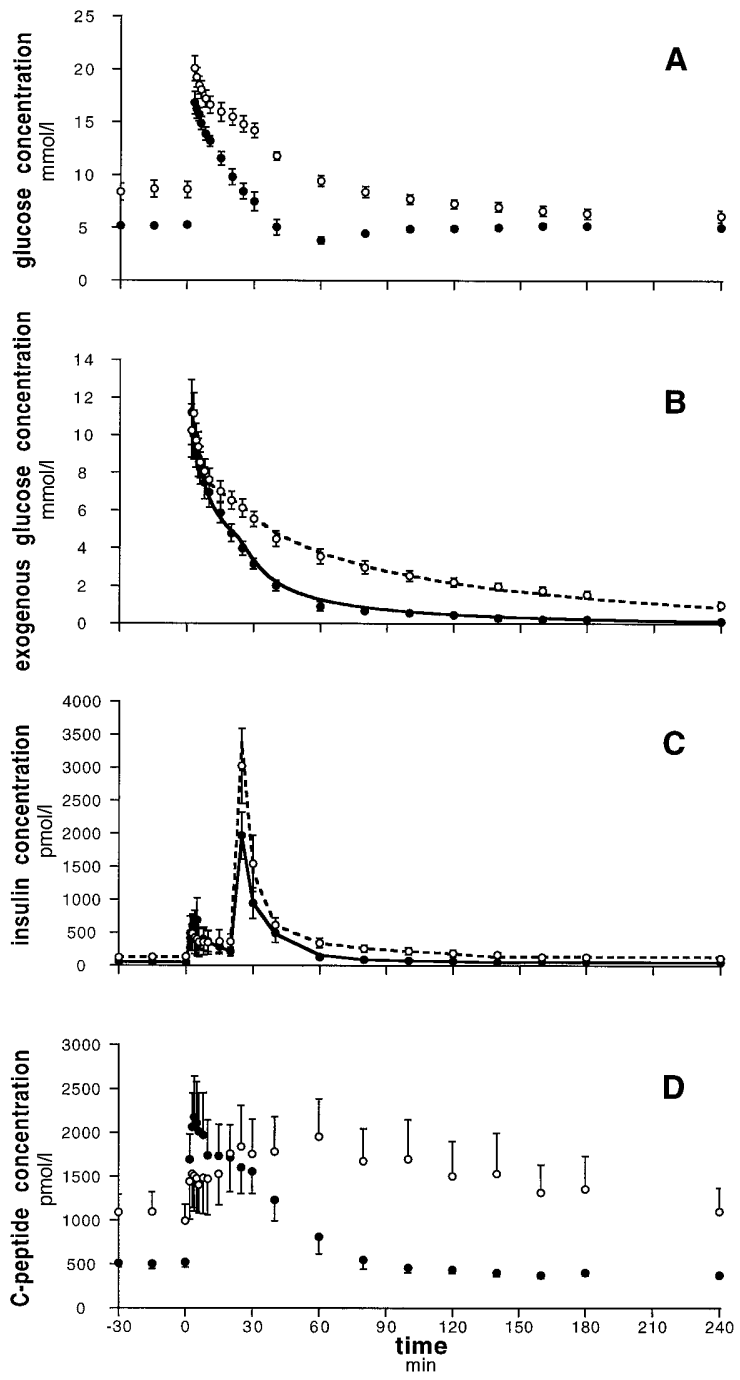

Fig. 2. Glucose (A), exogenous glucose (B), insulin $(\mathbf{C})$ and C-peptide (D) concentration in normal (- - ) and NIDDM (---O--) subjects. The lines represent the mean model-predicted exogenous glucose concentration (panel B) and smoothed insulin concentration (panel C). The SEM mean model predictions and smoothing are similar to that of the data points, and are is not reported for clarity

$\mathrm{PSI}_{\mathrm{b}}=\mathrm{ISR}_{\mathrm{b}} / \mathrm{G}_{\mathrm{b}}$. A first-phase pancreatic sensitivity index $\left(\mathrm{PSI}_{1}, \mathrm{pmol} \cdot \mathrm{min}^{-1} \cdot \mathrm{m}^{-2} \cdot \mathrm{mmol} / \mathrm{l}^{-1}\right)$ was calculated as $\mathrm{PSI}_{1}=\mathrm{ISR}_{1} /\left(\right.$ peak glucose concentration $\left.-\mathrm{G}_{\mathrm{b}}\right)$. A secondphase pancreatic sensitivity index $\left(\mathrm{PSI}_{2}, \mathrm{pmol} \cdot \mathrm{min}^{-1} \cdot \mathrm{m}^{-2}\right.$. $\mathrm{mmol} / \mathrm{l}^{-1}$ ) was calculated as the ratio between $\mathrm{ISR}_{2}$ and the integral mean of the glucose concentration increment above the basal value from 0 min to the time instant at which glucose concentration fell below the basal level.
Statistical analysis. Data and results are presented as mean \pm SEM. The Wilcoxon signed rank test, and the Wilcoxon rank sum test were used for paired and unpaired comparisons, respectively.

\section{Results}

Data and model fit. Figure 2 shows the mean data; basal glucose and insulin concentrations are also reported in Table 1. Panel B shows the mean exogenous glucose concentration in normal and NIDDM subjects. The mean model prediction is represented by the lines. In both groups, at virtually all time points the mean difference between observed and model predicted insulin or glucose concentration (model residual) did not differ from zero by more than two standard errors of the difference.

Glucose kinetic parameters. The estimated model parameters are reported in Table 2 . In each individual study the coefficients of variation of the estimated parameters calculated by the least-squares algorithm were less than $10 \%$. This low value is likely to be an underestimate of the true estimation error [5]. In all subjects and at all times, the whole-body fractional extraction satisfied the constraint $0<\mathrm{E}(\mathrm{t})<1$.

The calculated physiological parameters of glucose kinetics are reported in Table 3. Significant differences between normal and NIDDM subjects were observed in both the basal and the incremental insulin sensitivity indices, and in the glucose clearance at $600 \mathrm{pmol} / \mathrm{l}$. Glucose production was not different in absolute terms, but hepatic insulin resistance was nevertheless present in NIDDM subjects, because basal insulin and glucose concentrations were remarkably higher in NIDDM than in normal subjects. Considering normal and NIDDM subjects together, the basal and the incremental insulin sensitivity indices were correlated $(R=0.69, p<0.02)$.

Minimal model analysis. The parameters calculated from the minimal model analysis of the tracer data are reported in Table 4 . These parameters are in agreement with those obtained with the circulatory model. The correlation coefficients between the two method were (normal and diabetic subjects pooled): basal glucose clearance, $R=0.90(p<0.0001)$; glucose clearance at $600 \mathrm{pmol} / 1, R=0.96(p<0.0001)$;

Table 2. Estimated model parameters. The coefficients of variation of the estimated parameters, as calculated from the leastsquares algorithm, were below $10 \%$

\begin{tabular}{lllllll}
\hline & $\alpha_{1}\left(\mathrm{~min}^{-1}\right)$ & $\alpha_{2}\left(\mathrm{~min}^{-1}\right)$ & $\beta\left(\mathrm{min}^{-1}\right)$ & $\gamma(1 / \mathrm{pmol})$ & $\vartheta$ & $\mathrm{E}_{\mathrm{b}}$ \\
\hline Normal glucose tolerance & $1.4 \pm 0.4$ & $0.13 \pm 0.01$ & $0.085 \pm 0.019$ & $1.6 \pm 0.210^{-4}$ & $0.73 \pm 0.03$ & $0.044 \pm 0.011$ \\
NIDDM & $1.0 \pm 0.1$ & $0.15 \pm 0.01$ & $0.093 \pm 0.030$ & $0.49 \pm 0.1710^{-4}$ & $0.68 \pm 0.05$ & $0.027 \pm 0.005$ \\
\hline
\end{tabular}

Data are mean \pm SEM 
Table 3. Parameters of glucose kinetics calculated using the circulatory model

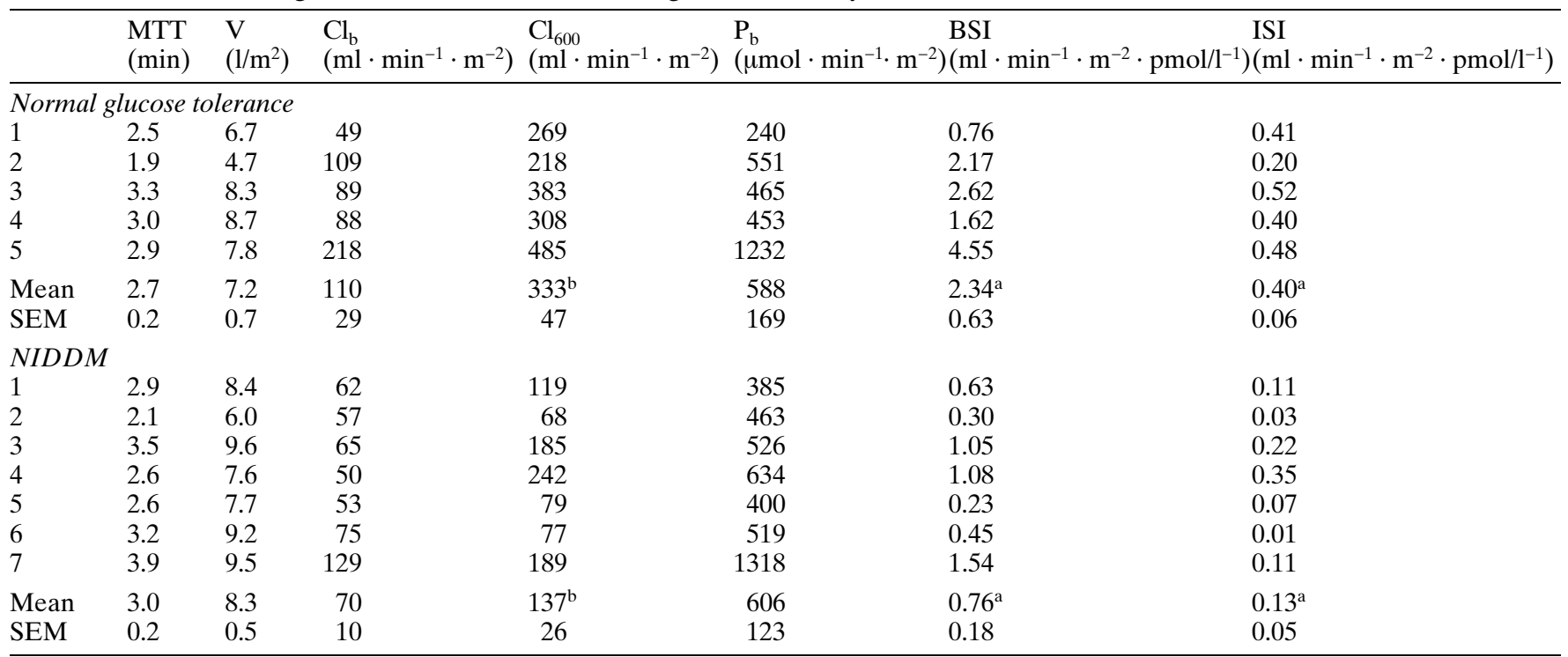

${ }^{\mathrm{a}} p<0.02 ;{ }^{\mathrm{b}} p<0.01$, NGT vs NIDDM

Table 4. Parameters of glucose kinetics calculated using the minimal model. The symbols are the same as those used for the circulatory model, but denote the minimal model calculated parameters

\begin{tabular}{llllll}
\hline & $\begin{array}{l}\mathrm{V} \\
\left(\mathrm{l} / \mathrm{m}^{2}\right)\end{array}$ & $\begin{array}{l}\mathrm{Cl}_{\mathrm{b}} \\
\left(\mathrm{ml} \cdot \mathrm{min}^{-1} \cdot \mathrm{m}^{-2}\right)\end{array}$ & $\begin{array}{l}\mathrm{Cl}_{600} \\
\left(\mathrm{ml} \cdot \mathrm{min}^{-1} \cdot \mathrm{m}^{-2}\right)\end{array}$ & $\begin{array}{l}\mathrm{BSI} \\
\left(\mathrm{ml} \cdot \mathrm{min}^{-1} \cdot \mathrm{m}^{-2} \cdot \mathrm{pmol} / \mathrm{l}^{-1}\right)\end{array}$ & $\begin{array}{l}\mathrm{ISI} \\
\left(\mathrm{ml} \cdot \mathrm{min}^{-1} \cdot \mathrm{m}^{-2} \cdot \mathrm{pmol} / \mathrm{l}^{-1}\right)\end{array}$ \\
\hline Normal glucose tolerance & $7.4 \pm 1.0$ & $131 \pm 46$ & $295 \pm 55^{\mathrm{b}}$ & $2.66 \pm 0.95$ & $0.30 \pm 0.11^{\mathrm{a}}$ \\
NIDDM & $8.5 \pm 0.7$ & $60 \pm 12$ & $112 \pm 20^{\mathrm{b}}$ & $0.70 \pm 0.20$ & $0.10 \pm 0.03^{\mathrm{a}}$ \\
\hline
\end{tabular}

${ }^{\mathrm{a}} p<0.05 ;{ }^{\mathrm{b}} p<0.01, \mathrm{NGT}$ vs NIDDM

basal insulin sensitivity index, $R=0.91(p<0.0001)$; incremental insulin sensitivity index, $R=0.78(p<$ $0.005)$.

Some differences between the two approaches were also found. With the minimal model, the basal and incremental insulin sensitivity indices were not correlated $(R=0.12, p \approx 0.7)$. The difference in basal insulin sensitivity index between normal and diabetic subjects did not reach statistical significance $(p \approx 0.062)$. Considering all subjects together, the glucose clearance at $600 \mathrm{pmol} / \mathrm{l}$ was lower with the minimal model than with the circulatory model $(p<0.02)$.

Insulin secretion. The time course of insulin secretion in normal and NIDDM subjects is reported in Figure 3. As the insulin response varied considerably in diabetic subjects (Table 5), basal insulin secretion $\left(\mathrm{ISR}_{\mathrm{b}}\right)$ and pancreatic sensitivity $\left(\mathrm{PSI}_{\mathrm{b}}\right)$ were not statistically different in the two groups. The first-phase secretion was impaired in NIDDM subjects, as assessed by both the secretion integral index $\mathrm{ISR}_{1}$ and the corresponding pancreatic sensitivity index $\mathrm{PSI}_{1}$ (Table 5). Considering normal and NIDDM subjects together, the pancreatic sensitivity indices $\mathrm{PSI}_{\mathrm{b}}$ and $\mathrm{PSI}_{2}$ were correlated $(R=0.75, p<0.005)$.

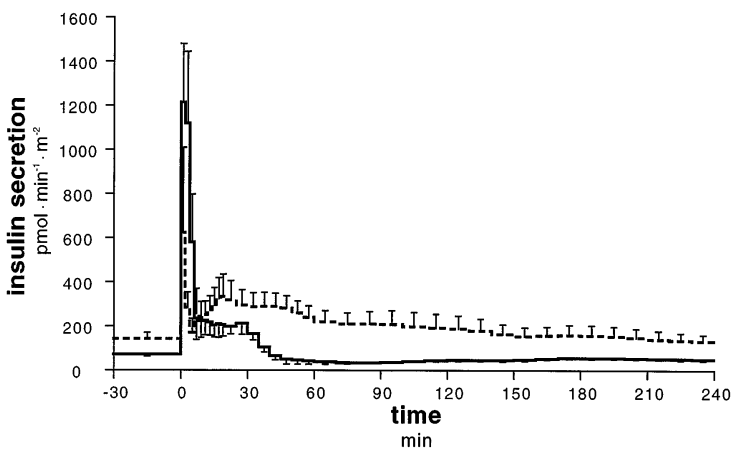

Fig. 3. Insulin secretion in normal (-) and NIDDM (---) subjects

Basal insulin sensitivity and pancreatic sensitivity. Figure 4 shows the relationship between basal pancreatic sensitivity $\left(\mathrm{PSI}_{\mathrm{b}}\right.$ ) and basal insulin sensitivity (BSI). The sensitivity indices of normal subjects and of a subgroup of diabetic subjects with high insulin response lay on the same straight line on the logarithmic plot $\left(\mathrm{PSI}_{\mathrm{b}}=18 \mathrm{BSI}^{-0.38}, R=0.95, p<0.0001\right)$. The $\mathrm{PSI}_{\mathrm{b}}$ values of the remaining diabetic subjects (with low insulin response) fell below the line. This result indicates the existence of a compensatory mechanism that increases beta-cell sensitivity when 
Table 5. Parameters of insulin secretion

\begin{tabular}{|c|c|c|c|c|c|c|}
\hline & $\mathrm{ISR}_{\mathrm{b}}$ & $\mathrm{ISR}_{1}$ & $\mathrm{ISR}_{2}$ & $\mathrm{PSI}_{\mathrm{b}}$ & $\mathrm{PSI}_{1}$ & $\mathrm{PSI}_{2}$ \\
\hline & \multicolumn{3}{|c|}{$\left(\mathrm{pmol} \cdot \min ^{-1} \cdot \mathrm{m}^{-2}\right)$} & \multicolumn{3}{|c|}{$\left(\mathrm{pmol} \cdot \mathrm{min}^{-1} \cdot \mathrm{m}^{-2} \cdot \mathrm{mmol} / \mathrm{l}^{-1}\right)$} \\
\hline \multicolumn{7}{|c|}{ Normal glucose tolerance } \\
\hline 1 & 94 & 1649 & 185 & 19 & 120 & 34 \\
\hline 2 & 71 & 309 & 39 & 14 & 36 & 9 \\
\hline 3 & 75 & 1102 & 237 & 14 & 76 & 39 \\
\hline 4 & 58 & 910 & 72 & 11 & 60 & 10 \\
\hline 5 & 55 & 530 & 104 & 10 & 42 & 17 \\
\hline Mean & 71 & $900^{\mathrm{a}}$ & 127 & 14 & $67^{\mathrm{a}}$ & 22 \\
\hline SEM & 7 & 233 & 37 & 2 & 15 & 6 \\
\hline \multicolumn{7}{|c|}{$N I D D M$} \\
\hline 1 & 157 & 76 & 93 & 25 & 7 & 18 \\
\hline 2 & 218 & 21 & 135 & 27 & 2 & 33 \\
\hline 3 & 68 & 2 & 95 & 8 & 0.2 & 26 \\
\hline 4 & 52 & 59 & 14 & 4 & 3 & 2 \\
\hline 5 & 244 & 884 & 252 & 32 & 53 & 55 \\
\hline 6 & 167 & 372 & 196 & 24 & 10 & 47 \\
\hline 7 & 82 & 113 & 62 & 8 & 9 & 12 \\
\hline Mean & 141 & $218^{\mathrm{a}}$ & 121 & 18 & $12^{\mathrm{a}}$ & 28 \\
\hline SEM & 28 & 120 & 31 & 4 & 7 & 7 \\
\hline
\end{tabular}

${ }^{\mathrm{a}} p<0.02$, normal glucose tolerance vs NIDDM

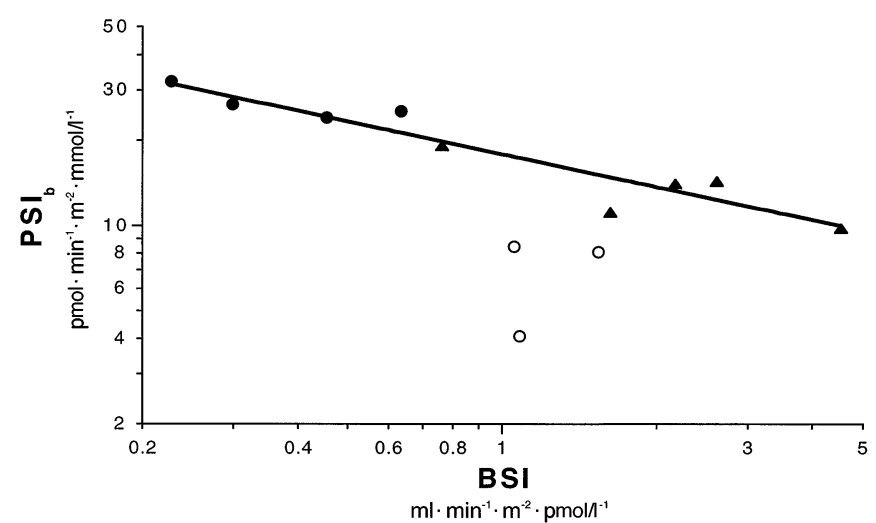

Fig. 4. Relationship between basal pancreatic sensitivity index $\left(\mathrm{PSI}_{\mathrm{b}}\right)$ and basal insulin sensitivity index (BSI). Triangles: normal subjects; Circles: NIDDM subjects with high (closed symbols) or low (open symbols) insulin response. The regression line represents the equation $\mathrm{PSI}_{\mathrm{b}}=18 \mathrm{BSI}^{-0.38}$, which appears as a linear relationship on the bi-logarithmic plot

peripheral insulin sensitivity decreases. In some diabetic subjects this compensatory mechanism is apparently the same as in normal subjects, while a subgroup of diabetic subjects (nos. 3, 4, 7) showed a markedly impaired compensation. These subjects had the highest basal glucose concentration values $(8.1,12.8,10.2 \mathrm{mmol} / \mathrm{l} \mathrm{vs}$ a range of $6.1-8.1 \mathrm{mmol} / \mathrm{l}$ in the remaining subjects).

\section{Discussion}

This work shows that the tracer-modified IVGTT is a suitable test for calculating key parameters of glucose metabolism and insulin secretion, provided that ap- propriate modelling analysis is employed. The use of a tracer and a glucose model that is compatible with the current knowledge on glucose kinetics thus overcomes the limitations of the simplified approaches, such as the minimal model, and makes the IVGTT competitive with the hyperglycaemic glucose clamp, that does not require modelling but is experimentally more laborious.

Experimental protocol and modelling analysis have been designed to overcome the two major limitations of the minimal model, i.e. the monocompartmental representation of glucose kinetics, that ignores the process of distribution of glucose in the body after its injection, and the inadequacy of the description of the glucose production process [3]. Although these model oversimplifications do not prevent the minimal model from giving a reasonable estimate of insulin sensitivity $\left(\mathrm{S}_{\mathrm{I}}\right)$, they are the cause of significant problems. Among these problems are the negative $S_{I}$ values sometimes obtained in NIDDM, the ambiguity of interpretation of the minimal model parameters $\left(S_{I}\right.$ and $\left.S_{G}\right)$, and the possible dependence of $\mathrm{S}_{\mathrm{I}}$ and $\mathrm{S}_{\mathrm{G}}$ on the experimental protocol [e.g. 2, 3, $23,24]$.

The problem of modelling glucose production has been avoided by using a glucose tracer in the IVGTT, as done in previous studies $[8,25,26]$. The complexity of the mechanisms of glucose production regulation by glucose, insulin and other factors makes it hard to develop an adequate mathematical model. Thus, a tracer is required to obtain reliable physiological parameters of glucose metabolism, although this restricts the field of application of the test. With the stable-isotope tracer, however, ethical problems are not present, and the protocol retains the experimental simplicity of the more traditional unlabelled test.

To give a realistic representation of glucose kinetics a circulatory model has been used. Circulatory models combine the classical so-called model-independent organ kinetic methods $[14,15]$, appropriately extended $[11,13]$, with an explicit representation of the circulatory loop. As the original organ kinetic methods, circulatory models do not require assumptions on the internal structure of the organs. The circulatory model accounts for glucose distribution by representing the whole-body response to a tracer bolus in steady state as a three-exponential function, in agreement with the experimental observations [e.g. 27-29).

More generally, the circulatory model gives a representation of the glucose system that is in agreement with the physiological knowledge. Cardiac output, which cannot be estimated in these experiments, has been derived from the literature. A fixed value per square meter of body surface area (also known as cardiac index) has been used to properly account for body size also in obesity. An error on the cardiac output value of an individual subject may be present, but 
this error does not affect all the estimated model parameters in the same way. Glucose clearance in contrast, for instance, to whole-body fractional extraction, is in fact not expected to depend substantially on this assumption, as it is totally independent of cardiac output in steady-state conditions. The same consideration applies to the glucose distribution volume and to the parameters derived from glucose clearance, i. e. glucose production and the insulin sensitivity indices.

In the model, the effect that insulin exerts on glucose kinetics is to increase the glucose fractional extraction of the aggregate of the body tissues, or, equivalently, the whole-body clearance. This choice is supported by the well-known finding that insulin increases the glucose fractional extraction in the insulin-dependent tissues, particularly muscle. A linear relationship between insulin concentration and glucose clearance has been assumed, and the incremental insulin sensitivity index (ISI) has been defined as the slope of this line. This relationship is known to be approximately linear in the physiological range of insulin concentrations, while glucose clearance tends to saturate at supraphysiological insulin levels. Although in the IVGTT plasma insulin concentration reaches a peak value of about $2400 \mathrm{pmol} / \mathrm{l}(400 \mu \mathrm{U} /$ $\mathrm{ml}$ ) after the infusion of exogenous insulin, on average the value of plasma insulin concentration in the first $60 \mathrm{~min}$ is only about $600 \mathrm{pmol} / \mathrm{l}(100 \mu \mathrm{U} / \mathrm{ml})$, i.e. in the physiologic range. It is thus expected that ISI is comparable with the estimate of the slope of insulin concentration-glucose clearance curve obtained with a classical hyperinsulinaemic glucose clamp at approximately $600 \mathrm{pmol} / \mathrm{l}$ insulin concentration (the so-called $\mathrm{S}_{\mathrm{IP}(\mathrm{clamp})}$, e.g. [30].

The dynamic effect of insulin on glucose clearance is represented by a variable $[\mathrm{Z}(\mathrm{t}), \mathrm{Eq} .4]$ that is insulin concentration delayed. This model of insulin action, which is also employed in the minimal model and in the model of glucose kinetics developed by Insel and colleagues [28], is in agreement with the general finding of euglycaemic hyperinsulinaemic glucose clamp studies that a brisk rise in plasma insulin concentration produces a near-monoexponential rise of glucose disappearance.

In summary, although the model presented here cannot account for all the complex factors that are known to influence glucose kinetics, for a more detailed discussion see [5], it removes a major assumption of the minimal model, i. e. the monocompartmental assumption, and is based on known physiological facts. This has two consequences: first, using the model, parameters that have an unambiguous physiological meaning, such as glucose clearance, volume and production are calculated; second, the estimated parameters' values are in agreement with literature values obtained with independent methods. Ferrannini et al. [29] reported in normal subjects the values $\mathrm{V}=$
$244 \pm 44 \mathrm{ml} / \mathrm{kg}, \mathrm{Cl}_{\mathrm{b}}=2.5 \pm 0.1 \mathrm{ml} \cdot \mathrm{min}^{-1} \cdot \mathrm{kg}^{-1}, \mathrm{Cl}_{660}=$ $9.1 \pm 0.9 \mathrm{ml} \cdot \mathrm{min}^{-1} \cdot \mathrm{kg}^{-1}$ (glucose clearance at approximately $660 \mathrm{pmol} / \mathrm{l}$ insulin concentration), and $\mathrm{P}_{\mathrm{b}}=$ $12 \pm 0.7 \mu \mathrm{mol} \cdot \mathrm{min}^{-1} \cdot \mathrm{kg}^{-1}$. These values agree with those of Table 3, that expressed in the same units are $\mathrm{V}=186 \pm 15 \mathrm{ml} / \mathrm{kg}, \mathrm{Cl}_{\mathrm{b}}=2.8 \pm 0.7 \mathrm{ml} \cdot \mathrm{min}^{-1} \cdot \mathrm{kg}^{-1}$, $\mathrm{Cl}_{660}=9.2 \pm 1.1 \mathrm{ml} \cdot \mathrm{min}^{-1} \cdot \mathrm{kg}^{-1}$, and $\mathrm{P}_{\mathrm{b}}=15 \pm 4 \mu \mathrm{mol}$ $\cdot \mathrm{min}^{-1} \cdot \mathrm{kg}^{-1}$. The value of the average slope of the relationship between insulin concentration and glucose clearance calculated from the mean results of Ferrannini et al. [29] would be approximately $10 \mathrm{ml} \cdot \mathrm{min}^{-1}$. $\mathrm{kg}^{-1} \cdot \mathrm{nmol} / \mathrm{l}^{-1}$, which compares well with an ISI of $10.4 \mathrm{ml} \cdot \mathrm{min}^{-1} \cdot \mathrm{kg}^{-1} \cdot \mathrm{nmol} / \mathrm{l}^{-1}$ obtained from the present experiments. In the study by Saad et al. [23], the incremental insulin sensitivity $\mathrm{S}_{\mathrm{IP}(\text { clamp })}$ converted to the units of ISI was $0.52 \pm 0.07 \mathrm{ml} \cdot \mathrm{min}^{-1} \cdot \mathrm{m}^{-2}$. $\mathrm{pmol} / \mathrm{l}^{-1}$, which is similar to the ISI value reported in Table $3\left(0.40 \pm 0.06 \mathrm{ml} \cdot \mathrm{min}^{-1} \cdot \mathrm{m}^{-2} \cdot \mathrm{pmol} / \mathrm{l}^{-1}\right)$. As to the coefficients of variation of the estimated parameters, the present analysis may be less precise than other model independent methods [5]. However, the precision was sufficient to detect statistically significant differences in insulin sensitivity in the small group of subjects considered in this study.

The validity of the present analysis is also supported by the fact that it fully reproduces, even in a limited number of subjects, the findings that are part of the current knowledge on insulin sensitivity and secretion in NIDDM. The results of this study are representative of NIDDM as summarized by DeFronzo [31]: "in the earliest stage of type 2 diabetes both hepatic and peripheral tissue resistance to insulin is well-established and is offset by the presence of compensatory hyperinsulinaemia. Overt diabetes develops only in individuals whose pancreas is unable to meet the increased and sustained demand for insulin secretion".

Recently, a two-compartment model for the assessment of glucose kinetic parameters from a similar test has been published, with application to normal subjects [21]. This approach and the present analysis go in the same direction, as both overcome the monocompartmental assumption of the minimal model. Indeed, the circulatory model describes the tracer disappearance curve in steady state with three rather than two exponentials. However, the lack of the fastest exponential is term, which naturally arises in the circulatory model from the monoexponential heartlungs response, is not a major limitation in the description of glucose distribution [32]. The two-compartment model yields parameters of glucose kinetics some of which are similar to those obtained with the circulatory model, such as glucose clearance, and are in agreement with the literature.

Experimental testing of the accuracy of these two approaches is not possible, as in this study and in [21] an independent assessment of the glucose kinetic parameters is not available. As both models contain 
assumptions, their validity should be judged from the ability to estimate the glucose kinetic parameters accurately, rather than in principle. A comment on the reasons of the choice of a circulatory model in the present analysis is however appropriate. Circulatory models have been developed from the so-called model-independent kinetic methods originally proposed by Zierler $[14,15]$ specifically to overcome some problems of compartmental models $[11,13]$. These problems include the fact that compartmental models are not a physical description of the system, and that the results depend on the specific compartmental configuration adopted (arrangement of compartments, choice of the compartment from which glucose is removed, etc). In the present context, which requires a model for non-steady-state glucose kinetics, different compartmental structures have been proposed $[21,32,33]$ that are not equivalent. Furthermore, in non-steady-state none of the compartmental structures is equivalent to the circulatory model, that is a physical representation of the system (this can be shown by extension of the theorem of Ref. [11], Appendix C). The effects of the model configuration are not exactly known, but the problems mentioned above, which do not exist with circulatory models, remain a concern in the use of compartmental analysis.

The present analysis has also the advantage of employing the insulin-modified IVGTT, while the standard IVGTT has been used previously [21]. The evaluation of the performance of a model with the insulin-modified IVGTT is essential, as the standard IVGTT cannot be employed in NIDDM subjects. This work reports results in both normal and NIDDM subjects, showing that the model gives satisfactory results in NIDDM, and is able to detect the expected differences between these groups.

Vicini et al. [21] have shown that the minimal model analysis of the IVGTT tracer data can also give physiologically meaningful parameters if minimal model parameters $S_{I}$ and $S_{G}$ are multiplied by the minimal model distribution volume. In contrast to the classical minimal model approach, this improved non-standard analysis is in good agreement with the two-compartment model, and shows that the tracer is a major reason of improvement of the minimal model performance. A good concordance between these non-standard minimal model parameters and the analogous parameters of the circulatory model is thus expected. The present analysis confirms this expectation, but also shows that the two analyses do not fully coincide. As for the two-compartment model, in lack of an independent assessment of the glucose kinetic parameters, it is impossible to evaluate the accuracy of the two approaches. However, with the minimal model the difference of basal insulin sensitivity did not reach statistical significance, and a correlation between insulin sensitivity at basal and hyperinsulinaemic levels was not found. These results suggest that the circulatory model may still be an improvement over the non-standard tracerbased minimal model analysis.

An inverse relationship between insulin sensitivity and secretion was found in several previous studies e.g. [34-36]. In this study, even with a limited number of subjects, an analogous relationship was found between the basal pancreatic sensitivity index $\mathrm{PSI}_{\mathrm{b}}$ and the basal insulin sensitivity index BSI. This relationship $\left(\mathrm{PSI}_{\mathrm{b}}=18 \mathrm{BSI}^{-0.38}\right)$ accurately predicted basal pancreatic sensitivity as a function of basal insulin sensitivity in both normal subjects and a subgroup of NIDDM subjects, while in some diabetic subjects basal pancreatic sensitivity was lower than that predicted by this relationship. These uncompensated subjects were the less insulin resistant but had the higher basal glycaemic levels. Although the number of subjects is certainly insufficient to draw general conclusions, this finding supports the concept that in NIDDM the defect of insulin secretion is independent of the defect of insulin sensitivity.

It has been observed that the graph representing the relationship between fasting insulin and glucose concentration in a population including normal, intolerant, and NIDDM subjects has a characteristic shape [31]. When glucose concentration is reported on the abscissa of the graph and insulin concentration on the ordinate, the relationship exhibits as an invertedU shape, with a peak of insulin concentration at about $8 \mathrm{mmol} / \mathrm{l}(\sim 140 \mathrm{mg} / \mathrm{dl})$ glucose concentration. The reason for this shape is clear. The part of the graph left to the peak represents the subjects that compensate insulin resistance with insulin hypersecretion. In these subjects, the increase in insulin resistance is accompanied by an increase in insulin secretion, that is sufficiently potent to keep glucose concentration below the $8 \mathrm{mmol} / \mathrm{l}$ threshold. In the subjects represented by the right part of the graph, the pancreatic response is insufficient to compensate for the increase in insulin resistance. Glucose concentration rises above $8 \mathrm{mmol} / \mathrm{l}$, and insulin concentration progressively falls as the pancreatic function worsens. The significance of the $8 \mathrm{mmol} / \mathrm{l}$ glucose concentration threshold remains, however, unexplained [37]. The present analysis of the beta cells' compensatory mechanism (Fig. 5) suggests an explanation for this phenomenon. The $8 \mathrm{mmol} / \mathrm{l} \mathrm{critical} \mathrm{value} \mathrm{of} \mathrm{glucose} \mathrm{con-}$ centration is not a threshold beyond which a progressive loss of pancreatic function begins, but is the maximum glucose concentration value reached at any reasonable degree of insulin resistance when the compensatory mechanism is normal. In fact, when the compensation law is normal (the line in Fig. 5), basal glucose concentration is given by $G_{b}=\sqrt{P_{b} / k_{B S I}^{0.62}}$ ( $\mathrm{k}$ is a constant, see Appendix B). As long as basal glucose production does not decrease with increasing basal insulin resistance (i.e. with decreasing BSI), which is reasonable to think, $G_{b}$ has a maximum (the 
$8 \mathrm{mmol} / \mathrm{l}$ peak) corresponding to the minimum BSI. Thus, the left part of the inverted-U curve represents the subjects with a normal compensatory mechanism (i. e. includes the subjects on the line of Fig.5), while the right part of the curve represents the subjects with an impaired compensation (i.e. includes the subjects below the line of Fig. 5).

The present approach has the limitation that the role of glucose production remains not well defined. With the use of a tracer glucose production during the IVGTT could be calculated. However, the initial suppression of glucose production and its successive recovery depend in a complex way not only on insulin and glucose concentration, that are measured, but also on unmeasured factors such as glucagon, counterregulatory hormones, and possibly non-esterified fatty acids. This makes the determination of physiologically meaningful indexes of hepatic sensitivity difficult.

In conclusion, this work proposes a new approach for the analysis of the tracer-modified IVGTT with which a rich set of physiological parameters characterizing glucose metabolism and insulin secretion can be obtained. The results obtained in normal and NIDDM subjects are in agreement with the literature and with the current knowledge on insulin sensitivity and secretion in NIDDM. The analysis also reveals new aspects of the relationship between insulin sensitivity and secretion. Thus, with appropriate modelling analysis the tracer-modified IVGTT is a powerful test to quantify insulin sensitivity and secretion and their relationships.

Acknowledgements. The author is grateful to Angelo Avogaro and Anna Valerio of the Department of Clinical and Experimental Medicine of the University of Padova, Italy, for their generosity in providing experimental data and precious suggestions.

\section{Appendix A}

How the differential equations of the circulatory model of Figure 1 are obtained.

Basic differential equation. If the impulse response of an organ is the single-exponential function $\mathrm{r}(\mathrm{t})=\mathrm{K} \alpha \mathrm{e}^{-\alpha \mathrm{t}}$, the convolution expressing the relationship between outlet $\left[\mathrm{C}_{\text {out }}(\mathrm{t})\right]$ and inlet $\left[\mathrm{C}_{\text {in }}(\mathrm{t})\right]$ concentration (Eq. 1) can be represented using the differential equation

$\frac{\mathrm{dC}_{\text {out }}(\mathrm{t})}{\mathrm{dt}}=-\alpha \mathrm{C}_{\text {out }}(\mathrm{t})+\alpha \mathrm{KC}_{\text {in }}(\mathrm{t})$

Heart-lungs block. The heart-lungs block of the circulatory model of Figure 1 has the impulse response $r_{H L}(t)=\lambda e^{-\lambda t}(E q$. $2)$. Inlet concentration is glucose concentration in the right atrium $\left[\mathrm{G}_{\mathrm{RA}}(\mathrm{t})\right]$, and outlet concentration is arterial glucose concentration $\left[\mathrm{G}_{\mathrm{A}}(\mathrm{t})\right]$. The convolution expressing the relationship between $\mathrm{G}_{\mathrm{A}}(\mathrm{t})$ and $\mathrm{G}_{\mathrm{RA}}(\mathrm{t})$ can be represented using Eq. $\mathrm{A} 1(\alpha=\lambda$ and $\mathrm{K}=1$ in this case):
$\frac{\mathrm{dG}_{\mathrm{A}}(\mathrm{t})}{\mathrm{dt}}=-\lambda \mathrm{G}_{\mathrm{A}}(\mathrm{t})+\lambda \mathrm{G}_{\mathrm{RA}}(\mathrm{t})$

Periphery block. The periphery block of the circulatory model of Figure 1 has the impulse response (Eq. 3)

$$
\begin{aligned}
\mathrm{r}_{\mathrm{P}}(\mathrm{t})= & {\left[\vartheta \alpha_{1} \mathrm{e}^{-\alpha_{1} \mathrm{t}}+(1-\vartheta) \alpha_{2} \mathrm{e}^{-\alpha_{2} \mathrm{t}}\right](1-\mathrm{E})=} \\
& \vartheta(1-\mathrm{E}) \alpha_{1} \mathrm{e}^{-\alpha_{1} \mathrm{t}}+(1-\vartheta)(1-\mathrm{E}) \alpha_{2} \mathrm{e}^{-\alpha_{2} \mathrm{t}}
\end{aligned}
$$

Inlet concentration is arterial glucose concentration $\left[\mathrm{G}_{\mathrm{A}}(\mathrm{t})\right]$, and outlet concentration is mixed-venous glucose concentration $\left[\mathrm{G}_{\mathrm{MV}}(\mathrm{t})\right]$. The convolution expressing the relationship between $G_{M V}(t)$ and $G_{A}(t)$ can be also represented using Eq. A1. In this case, $G_{M V}(t)$ is the sum of two terms, $G_{1}(t)$ and $\mathrm{G}_{2}(\mathrm{t})$, one for each exponential of $\mathrm{r}_{\mathrm{P}}(\mathrm{t})$ (Eq. A3). $\mathrm{G}_{1}(\mathrm{t})$ is obtained from Eq. A1 setting $\alpha=\alpha_{1}$ and $K=\vartheta(1-E)$, while $G_{2}(t)$ is obtained setting $\alpha=\alpha_{2}$ and $K=(1-\vartheta)(1-E)$.

Thus, the convolution expressing the relationship between $G_{M V}(t)$ and $G_{A}(t)$ can be represented with the differential equations

$$
\begin{aligned}
& \frac{\mathrm{dG}_{1}(\mathrm{t})}{\mathrm{dt}}=-\alpha_{1} \mathrm{G}_{1}(\mathrm{t})+\alpha_{1} \vartheta(1-E) \mathrm{G}_{\mathrm{A}}(\mathrm{t}) \\
& \frac{\mathrm{dG}_{2}(\mathrm{t})}{\mathrm{dt}}=-\alpha_{2} \mathrm{G}_{2}(\mathrm{t})+\alpha_{2}(1-\vartheta)(1-E) \mathrm{G}_{\mathrm{A}}(\mathrm{t}) \\
& \mathrm{G}_{\mathrm{MV}}(\mathrm{t})=\mathrm{G}_{1}(\mathrm{t})+\mathrm{G}_{2}(\mathrm{t})
\end{aligned}
$$

$\mathrm{E}$ is the glucose fractional extraction of the periphery. During the IVGTT, the dependence of glucose fractional E on insulin concentration is represented by Eqs. 4-5.

Circulatory model differential equations. The glucose flux entering the right atrium is the product of cardiac output $(\mathrm{F})$ and glucose concentration in the right atrium, $\mathrm{FG}_{\mathrm{RA}}(\mathrm{t})$. This flux is the sum of the glucose flux returning from the periphery, $\mathrm{FG}_{\mathrm{MV}}(\mathrm{t})$, and the exogenous glucose infusion $\mathrm{J}$ (Fig. 1). Thus,

$\mathrm{G}_{\mathrm{RA}}(\mathrm{t})=\mathrm{G}_{\mathrm{MV}}(\mathrm{t})+\mathrm{J} / \mathrm{F}$

By combining Eqs. A2, A4, A5, 4, and 5 a set of four differential equation describing exogenous glucose concentration during the IVGTT $\left[\mathrm{G}_{\mathrm{A}}(\mathrm{t})\right]$ is obtained:

$$
\begin{aligned}
& \frac{\mathrm{dG}_{\mathrm{A}}(\mathrm{t})}{\mathrm{dt}}=-\lambda \mathrm{G}_{\mathrm{A}}(\mathrm{t})+\lambda\left[\mathrm{G}_{1}(\mathrm{t})+\mathrm{G}_{2}(\mathrm{t})+\mathrm{J} / \mathrm{F}\right] \\
& \frac{\mathrm{dG}_{1}(\mathrm{t})}{\mathrm{dt}}=-\alpha_{1} \mathrm{G}_{1}(\mathrm{t})+\alpha_{1} \vartheta\left[1-\mathrm{E}_{\mathrm{b}}-\gamma \mathrm{Z}(\mathrm{t})\right] \mathrm{G}_{\mathrm{A}}(\mathrm{t}) \\
& \frac{\mathrm{dG}_{2}(\mathrm{t})}{\mathrm{dt}}=-\alpha_{2} \mathrm{G}_{2}(\mathrm{t})+\alpha_{2}(1-\vartheta)\left[1-\mathrm{E}_{\mathrm{b}}-\gamma \mathrm{Z}(\mathrm{t})\right] \mathrm{G}_{\mathrm{A}}(\mathrm{t}) \\
& \frac{\mathrm{dZ}(\mathrm{t})}{\mathrm{dt}}=-\beta \mathrm{Z}(\mathrm{t})+\beta\left[\mathrm{I}(\mathrm{t})-\mathrm{I}_{\mathrm{b}}\right]
\end{aligned}
$$

In these equations, $\mathrm{J}$ is the known intravenous glucose infusion (represented as a delta function), $\mathrm{F}=2688 \mathrm{ml} \cdot \mathrm{min}^{-1} \cdot \mathrm{m}^{-2}$ is cardiac output, $\lambda=3.84 \mathrm{~min}^{-1}$ is a constant (see Modelling analysis section), $\mathrm{I}(\mathrm{t})$ is the insulin concentration during the IVGTT, $I_{b}$ is the basal value of insulin concentration, and $\alpha_{1}$, $\alpha_{2}, \beta, \gamma, \vartheta$ and $\mathrm{E}_{\mathrm{b}}$ are the model parameters to be estimated.

The numerical solution of the differential equations A6 requires that the insulin concentration increment, $\mathrm{I}(\mathrm{t})-\mathrm{I}_{\mathrm{b}}(\mathrm{Eq}$. A6d), is available at every time instant. For this purpose, the measured values of the insulin concentration increment have been smoothed and interpolated with a continuous function of time, as detailed previously [5]. 


\section{Appendix B}

Relationship between basal glucose concentration and basal insulin sensitivity.

By using the definitions of BSI $\left(\mathrm{BSI}=\mathrm{Cl}_{\mathrm{b}} / \mathrm{I}_{\mathrm{b}}\right)$ and $\mathrm{PSI}_{\mathrm{b}}$ $\left(\mathrm{PSI}_{\mathrm{b}}=\mathrm{ISR}_{\mathrm{b}} / \mathrm{G}_{\mathrm{b}}\right)$, the following expression for basal glucose concentration can be derived:

$\mathrm{G}_{\mathrm{b}}=\frac{\mathrm{P}_{\mathrm{b}}}{\mathrm{Cl}_{\mathrm{b}}}=\frac{\mathrm{P}_{\mathrm{b}}}{\text { BSI I }_{\mathrm{b}}}=\frac{\mathrm{P}_{\mathrm{b}}}{\mathrm{k}_{1} \text { BSI ISR }_{\mathrm{b}}}=\frac{\mathrm{P}_{\mathrm{b}}}{\mathrm{k}_{1} \text { BSI PSI }_{\mathrm{b}} \mathrm{G}_{\mathrm{b}}}$

where $\mathrm{k}_{1}=\mathrm{I}_{\mathrm{b}} / \mathrm{ISR}_{\mathrm{b}}$ is the reciprocal of basal insulin clearance (referred to portal insulin appearance). By inserting into Eq. $\mathrm{B} 1$ the expression that relates $\mathrm{PSI}_{\mathrm{b}}$ to BSI reported in Figure $4\left(\mathrm{PSI}_{\mathrm{b}}=18 \mathrm{BSI}^{-0.38}\right)$, and solving for $\mathrm{G}_{\mathrm{b}}$, one obtains

$\mathrm{G}_{\mathrm{b}}=\sqrt{\frac{\mathrm{P}_{\mathrm{b}}}{\mathrm{k}_{2} \mathrm{BSI}^{0.62}}}$

where $\mathrm{k}_{2}=18 \mathrm{k}_{1}$

Eq. B2 expresses basal glucose concentration as a function of basal insulin sensitivity (BSI) and basal glucose production (it is assumed that basal insulin clearance, and thus $\mathrm{k}_{2}$, is constant). This equation includes the pancreas compensation law $\mathrm{PSI}_{\mathrm{b}}=18 \mathrm{BSI}^{-0.38}$ and is thus valid in normal subjects and in diabetic subjects with high insulin response. Since it is expected that as insulin sensitivity decreases, basal glucose production does not decrease; basal glucose concentration is expected to have a maximum at the lowest BSI.

\section{References}

1. Bergman RN, Ider YZ, Bowden CR, Cobelli C (1979) Quantitative estimation of insulin sensitivity. Am J Physiol 236: E667-E677

2. Caumo A, Vicini P, Cobelli C (1996) Is the minimal model too minimal? Diabetologia 39: 997-1000

3. Mari A (1997) Assessment of insulin sensitivity with minimal model: role of model assumptions. Am J Physiol 272: E925-E934

4. Van Cauter E, Mestrez F, Sturis J, Polonsky KS (1992) Estimation of insulin secretion rates from C-peptide levels. Comparison of individual and standard kinetic parameters for C-peptide clearance. Diabetes 41: 368-377

5. Mari A, Valerio A (1997) A circulatory model for the estimation of insulin sensitivity. Control Eng Practice 5: 1747-1752

6. Kuzuya H, Blix PM, Horwitz DL, Steiner DF, Rubenstein AH (1977) Determination of free and total insulin and C-peptide in insulin-treated diabetes. Diabetes 26: 22-29

7. Cole RA, Soeldner JS, Dunn PJ, Bunn HF (1978) A rapid method for the determination of glycosylated hemoglobins using high pressure liquid chromatography. Metabolism 27: 289-301

8. Avogaro A, Bristow JD, Bier DM, Cobelli C, Toffolo G (1989) Stable-label intravenous glucose tolerance test minimal model. Diabetes 38: 1048-1055

9. Rosenblatt J, Chinkes D, Wolfe M, Wolfe RR (1992) Stable isotope tracer analysis by GC-MS, including quantification of isotopomer effects. Am J Physiol 263: E584-E596

10. Waterhouse C, Keilson J (1972) Transfer times across the human body. Bull Math Biophys 34: 33-44

11. Mari A (1993) Circulatory models of intact-body kinetics and their relationship with compartmental and noncompartmental analysis. J Theor Biol 160: 509-531

12. Mari A (1995) Determination of the single-pass impulse response of the body tissues with circulatory models. IEEE Trans Biom Eng 42: $304-312$

13. Mari A (1995) Calculation of organ and whole-body uptake and production with the impulse response approach. J Theor Biol 174: 341-353
14. Meier P, Zierler KL (1954) On the theory of the indicator-dilution method for measurement of blood flow and volume. J Appl Physiol 6: 731-744

15. Zierler KL (1961) Theory of the use of arteriovenous concentration differences for measuring metabolism in steady and non-steady states. J Clin Invest 40: 2111-2125

16. Lassen NA, Perl W (1979) Tracer kinetic methods in medical physiology. Raven Press, New York

17. Guyton AC (1976) Textbook of medical physiology. 5th. W.B. Saunders Company, Philadelphia

18. Chinard FP (1969) Exchanges across the alveolar-capillary barrier. In: Fishman AP, Hecht HH (eds) The pulmonary circulation and interstitial space. University of Chicago Press, Chicago, pp 79-98

19. Meyer EC, Ottaviano R (1974) Right lymphatic duct distribution volume in dogs. Relationship to pulmonary interstitial volume. Circ Res 35: 197-203

20. Perl W, Silverman F, Delea AC, Chinard FP (1976) Permeability of dog lung endothelium to sodium, diols, amides, and water. Am J Physiol 230: 1708-1721

21. Vicini P, Caumo A, Cobelli C (1997) The hot IVGTT two-compartment minimal model: indexes of glucose effectiveness and insulin sensitivity. Am J Physiol 273: E829-E841

22. Eaton RP, Allen RC, Schade DS, Erickson KM, Standefer J (1980) Prehepatic insulin production in man: kinetic analysis using peripheral connecting peptide behavior. J Clin Endorinol Metab 51: $520-528$

23. Saad MF, Anderson RL, Laws A et al. (1994) A comparison between the minimal model and the glucose clamp in the assessment of insulin sensitivity across the spectrum of glucose tolerance. Diabetes 43: 1114-1121

24. Finegood DT, Tzur D (1996) Reduced glucose effectiveness associated with reduced insulin release: an artifact of the minimal-model method. Am J Physiol 271: E485-E495

25. Avogaro A, Vicini P, Valerio A, Caumo A, Cobelli C (1996) The hot but not the cold minimal model allows precise assessment of insulin sensitivity in NIDDM subjects. Am J Physiol 270: E532-E540

26. Cobelli C, Pacini G, Toffolo G, Saccà L (1986) Estimation of insulin sensitivity and glucose clearance from minimal model: new insights from labeled IVGTT. Am J Physiol 250: E591-E598

27. Steele R, Wall JS, De Bodo RC, Altszuler N (1956) Measurement of size and turnover rate of body glucose pool by the isotope dilution method. Am J Physiol 187: 15-24

28. Insel PA, Liljenquist JE, Tobin JD et al. (1975) Insulin control of glucose metabolism in man. A new kinetic analysis. J Clin Invest 55: 1057-1066

29. Ferrannini E, Smith JD, Cobelli C, Toffolo G, Pilo A, De Fronzo RA (1985) Effect of insulin on the distribution and disposition of glucose in man. J Clin Invest 76: 357-364

30. Bergman RN, Prager R, Vølund A, Olefsky JM (1987) Equivalence of the insulin sensitivity index in man derived by the minimal model method and the euglycemic glucose clamp. J Clin Invest 79: 790-800

31. DeFronzo RA (1992) Pathogenesis of type 2 (non-insulin-dependent) diabetes mellitus: a balanced overview. Diabetologia 35: 389-397

32. Cobelli C, Toffolo G, Ferrannini E (1984) A model of glucose kinetics and their control by insulin, compartmental and noncompartmental approaches. Math Biosci 72: 291-315

33. Radziuk J, Norwich KH, Vranic M (1978) Experimental validation of measurements of glucose turnover in nonsteady state. Am J Physiol 234: E84-E93

34. Kahn SE, Prigeon RL, McCulloch DK et al. (1993) Quantification of the relationship between insulin sensitivity and beta-cell function in human subjects. Evidence for a hyperbolic function. Diabetes 42: $1663-1672$

35. Clausen JO, Borch-Johnsen K, Ibsen H et al. (1996) Insulin sensitivity index, acute insulin response, and glucose effectiveness in a population-based sample of 380 young healthy Caucasians. J Clin Invest 98: 1195-1209

36. Ferrannini E, Natali A, Bell P, Cavallo-Perin P, Lalic N, Mingrone G (1997) Insulin resistance and hypersecretion in obesity. J Clin Invest 100: $1166-1173$

37. Groop LC, Widén E, Ferrannini E (1993) Insulin resistance and insulin deficiency in the pathogenesis of type 2 (non-insulin-dependent) diabetes mellitus: errors of metabolism or of methods? Diabetologia 36: 1326-1331 